\title{
A Bidirectional Resonant DC-DC Converter for Electrical Vehicle Charging/Discharging Systems
}

\author{
Fahad Khan \\ College of Automation \\ Engineering \\ Nanjing University of Aeronautics \\ and Astronautics, Nanjing \\ 210016, China
}

\author{
Yu Tang \\ College of Automation \\ Engineering \\ Nanjing University of Aeronautics \\ and Astronautics, Nanjing \\ 210016, China
}

\author{
Gong Sicheng \\ College of Automation \\ Engineering \\ Nanjing University of Aeronautics \\ and Astronautics, Nanjing \\ 210016, China
}

\begin{abstract}
This paper presents a DC to DC bidirectional resonant converter to be used for bidirectional power transfer applications especially battery charging/discharging applications in electrical vehicles. It is similar to an LLC resonant converter but for bidirectional functionality, an additional inductor and capacitor have been added in the secondary side of the circuit to make the resonant network symmetric for operation in both forward and backward directions.
\end{abstract}

Zero Voltage Switching (ZVS) of the switches in the inverting stage is ensured. Also, the rectifier diodes in the secondary side turn off under ZCS. ZVS and ZCS result in reduction of losses and allow high frequency operation which leads to a reduction in the size of magnetic elements and filter capacitors thus reducing size, weight, volume and increasing power density.

In this paper, first an equivalent model of the converter is developed for a detailed analysis of the converter voltages and currents. Then simulations of the converter are carried out to verify the validity of the conceptual design.

\section{Keywords}

Bidirectional DC/DC; CLL-LC, EV Battery Charging/Discharging

\section{INTRODUCTION}

Bidirectional DC/DC converters possessing improved efficiency and high power density have been the focus of research in the area of on-board charging/discharging units for electrical vehicles or plug-in electrical vehicles (EV/PHEV). There exists a considerable amount of research work on the isolated bidirectional DC to DC converters [1]. The dual active bridge (DAB) converter topology enjoys great popularity. However, the conventional DAB converter suffers from a few drawbacks. For example, soft switching can be realized for a very narrow output and loading range using the modulation technique of the phase-shifted primary and secondary bridges. To widen the soft switching range of a $\mathrm{DAB}$ converter, a number of different DAB control techniques have been proposed in literature [2]-[7]. However, it fails to meet the requirements of the on-board charging/discharging unit voltage range. Moreover, the body diode recovery and turn-off losses of MOSFET switches present a big problem. Thus, most of the DAB converters employ IGBT switches. Lately much interest has been directed to the area of resonant topologies which offer soft-switching over a wide load range. In particular, the LLC resonant converter has been proposed and studied to increase overall efficiency, since this converter offers soft-switching feature [8]-[14]. However, the LLC resonant converter can transfer power in a unidirectional manner. When operated in the reverse mode, its gain is restricted to below unity.

As a novel topology, the CLLC bidirectional resonant converter has been studied and implemented in some energy storage applications. In [15], a symmetric LLC-type resonant topology has been put forth for a low-voltage DC power distribution system and high efficiency has been achieved. However, its voltage range is quite narrow thus it is unfit for use in a EV/PHEV application. A CLLC topology with wide voltage range was proposed in [16] and employed in the uninterrupted power supply system with an input/output range of $400 \mathrm{~V} / 48 \mathrm{~V}$. Nevertheless, in battery charging applications, its transformer ratio is unrealistic because of the considerable difference between the input and output voltages. In this paper, a CLL-LC type bidirectional DC/DC converter to fulfil all the requirements of on-board battery charging/discharging applications will be presented.

\section{ANALYSIS OF THE BI-DIRECTIONAL RESONANT CONVERTER}

The proposed converter is illustrated in

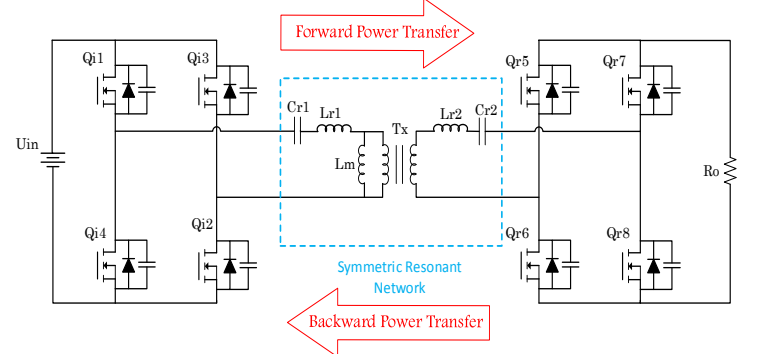

Fig. 1. It has a symmetric structure: the primary side circuit resembles the secondary side circuit connected by a symmetric high-frequency transformer.

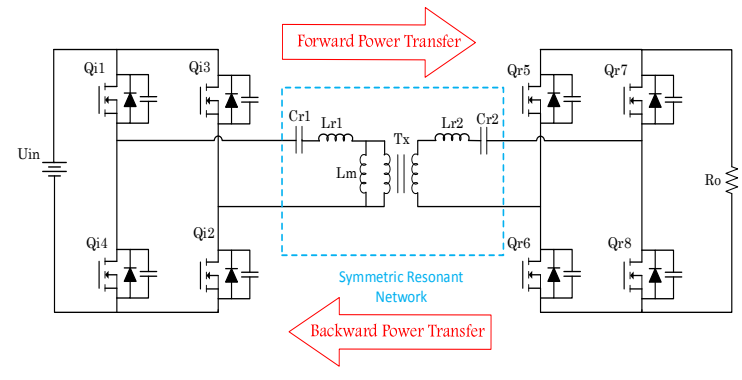


Fig. 1 Proposed Bidirectional Resonant Converter with Symmetric Resonant Network

The switches $Q_{i 1} \ldots Q_{i 4}$ in the primary inverting stage convert power from dc to ac to transfer it through the high frequency transformer. Using this transformer, the converter achieves galvanic isolation between the primary side and the secondary side. The leakage inductance of the transformer's primary and secondary windings is incorporated into the resonant inductors $L_{r 1} \quad$ and $L_{r 2}$, respectively. In addition,

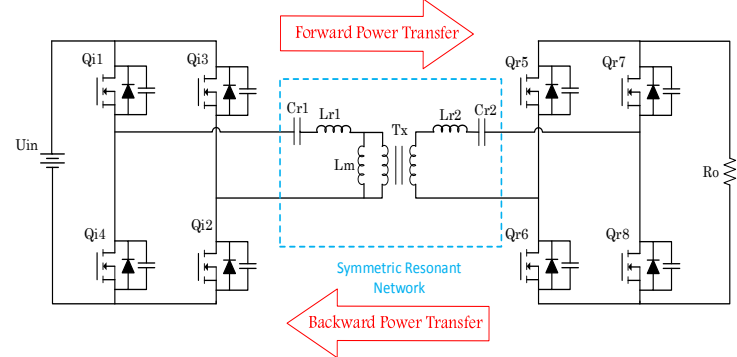

Fig. 1 shows power flow directions in the converter, which are defined as follows: power being transferred to the load from source (forward power flow direction) and power being transferred from source to load (backward power flow direction).

\subsection{Gain analysis through First Harmonic Approximation Model}

As the resonant tank works like a bandpass filter, commonly it is assumed that power transfer takes place mainly through the fundamental components of the voltages and currents. This is called the first harmonic approximation (FHA). In that sense, the square-wave applied to the resonant tank is represented by its fundamental component.

From

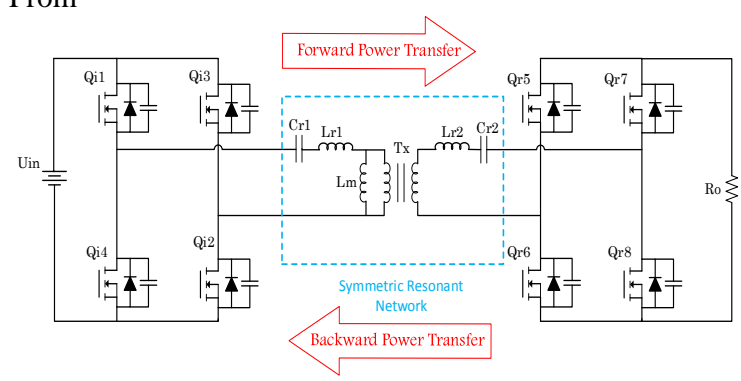

Fig. 1, the converter electrical circuit can be simplified to develop an expression for the gain of the resonant network in terms of switching frequency. The input voltage of the network, $u_{r i}$, is a square waveform which varies from $-U_{\text {in }}$ to $U_{i n}$. Using the Fourier series, it can be expressed as follows:

$$
u_{r i}(t)=\frac{4 U_{i n}}{\pi} \sum_{n=1,3,5, \ldots}^{\infty} \frac{1}{n} \sin \left(2 \pi n f_{s} t\right)
$$

where $t$ is the time parameter, $n$ is the integer parameter for the Fourier series expansion, and $f_{s}$ is the switching frequency of the inverting stage switches, respectively. The fundamental component of $u_{r i}, u_{r i, F H A}$, can be extracted from (1) using the FHA method as shown in the following equation:

$$
u_{r i, F H A}(t)=\frac{4 U_{i n}}{\pi} \sin \left(2 \pi f_{s} t\right)
$$

The rms value of $u_{r i, F H A}, U_{r i, F H A}$, can be calculated as

$$
U_{r i, F H A}=\frac{2 \sqrt{2}}{p} U_{i n}
$$

In the same way, the output voltage of the resonant network, $u_{r o}$, can be expressed as follows:

$$
u_{r o}(t)=\frac{4 U_{o}}{\pi} \sum_{n=1,3,5, \ldots}^{\infty} \frac{1}{n} \sin \left(2 \pi n f_{s} t-\phi\right)
$$

Where $\varphi$ is the phase shift with respect to the input voltage. Then, the fundamental component of $u_{r o}, u_{r o, F H A}$, can be extracted from (4) as follows:

$$
u_{r o, F H A}(t)=\frac{4}{\pi} U_{o} \sin \left(2 \pi f_{s} t-\phi\right)
$$

The rms value of $u_{r o, F H A}, U_{r o, F H A}$, can be calculated as

$$
U_{r o, F H A}=\frac{2 \sqrt{2}}{\pi} U_{o}
$$

The fundamental component of the rectifier current $i_{r c t}, i_{r c t, F H A}$ can also be expressed in the same manner as (2) and (5) as follows:

$$
i_{r c t, F H A}(t)=\sqrt{2} I_{r c t, F H A} \sin \left(2 \pi f_{s} t-\phi\right)
$$

Where $I_{r c t, F H A}$ is the rms value of $i_{r c t, F H A}$. Therefore, the average output current $I_{o}$ can be derived using (7) as follows:

$$
I_{o}=\frac{2}{T_{s}} \int_{0}^{\frac{T_{s}}{2}}\left|i_{r c t, F H A}(t)\right| \mathrm{d} t=2 \sqrt{2} I_{r c t, F H A}
$$

Since $u_{r o, F H A}$ and $i_{r c t, F H A}$ are in phase, the resistive load of the resonant network, $R_{o, e}$, is equal to the ratio of the instantaneous voltage and current as shown in (9) with the load resistance, $R_{o}$.

$$
R_{o, e}=\frac{U_{r o, F H A}}{I_{r c t, F H A}}=\frac{8}{\pi^{2}} R_{o}
$$

Based on the approach of fundamental harmonic approximation, the equations of the dc gain for both forward power transfer mode and backward power transfer mode can be expressed as follows.

$$
\begin{aligned}
& M_{F}=\frac{1}{n}\left|\frac{R_{o, e}}{R_{o, e}+Z_{L r 2}^{\prime}+Z_{C r 2}^{\prime}} \frac{\left(R_{0, e}+Z_{L r 2}^{\prime}+Z_{C r 2}^{\prime}\right) / / Z_{L m}}{Z_{L r 1}+Z_{C r 1}+\left(R_{o, e}+Z_{L r 2}^{\prime}+Z_{C r 2}^{\prime}\right) / / Z_{L m}}\right| \\
& M_{B}=\frac{1}{n}\left|\frac{R_{o, e}}{R_{o, e}+Z_{L r 1}^{\prime}+Z_{C r 1}^{\prime}} \frac{\left(R_{o, e}+Z_{L r 1}^{\prime}+Z_{C r 1}^{\prime}\right) / / Z_{L m}}{Z_{L r 2}+Z_{C r 2}+\left(R_{o, e}+Z_{L r 1}^{\prime}+Z_{C r 1}^{\prime}\right) / / Z_{L m}}\right|
\end{aligned}
$$

Where $\mathrm{M}_{\mathrm{F}}$ and $\mathrm{M}_{\mathrm{B}}$ are the forward and backward mode gains respectively and,

$$
\begin{gathered}
R_{o, e}=\left(8 n^{2} / \pi^{2}\right) R_{o}, \quad L_{r 2}^{\prime}=n^{2} \cdot L_{r 2} \\
C_{r 2}^{\prime}=\frac{C_{r 2}}{n^{2}}
\end{gathered}
$$




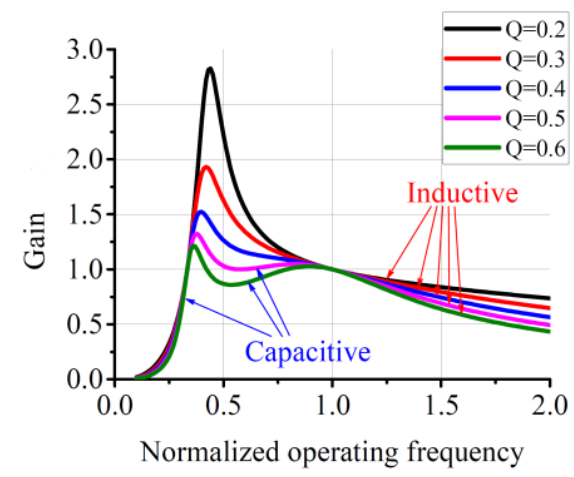

Fig. 2 Gain Curves of the converter Error! Reference source not found. shows the gain curves with respect to load current and normalized frequency, which is derived using (10). The peak value of the gain occurs at the low resonant frequency which includes the magnetizing inductance as a resonant component. At the series resonant frequency (without $\mathrm{Lm}$ ), the converter's gain is slightly higher than unity. Under light-load conditions, the converter has a high gain and the gain curve is steep. However, the overall value of the gain curve decreases under the heavy-load condition. A higher load results in the lower gain in the bidirectional CLL-LC resonant converter.

\subsection{Operation of the Converter}

Fig. 4 shows the different operational intervals of the proposed bidirectional CLL-LC resonant converter. This converter's operation has been divided into eight operational intervals during a single switching cycle. Intervals 1, 2, 3 and 4 repeat to intervals $4,5,6$ and 7 with different inverting and rectifying switch pairs. Intervals 2,3 and 4 are dead-time durations, intervals 1 and 5 are power transfer modes. The primary switches work in the inverting mode when power is transferred from the primary to the secondary side; however, the secondary switches remain OFF and the antiparallel diodes operate as rectifiers on the secondary side. Error! Reference source not found. gives theoretical waveforms showing the behavior of the converter for all intervals during a single switching cycle. In Error! Reference source not found., there are only the waveforms of the charging mode. However, in the discharging mode, the waveforms are precisely the same as the waveforms of the charging mode, because the primary inverting side and the secondary rectifying side are symmetric.

Detailed explanation and description of the operational intervals are given below:

Interval $1\left[t_{0}, t_{1}\right]$ : At the instant $t_{0}$, the switches $Q_{i 1}$ and $Q_{i 2}$ are conducting and power is transferred from the primary stage to the secondary stage. Resonance takes place between the series elements $C_{r l}, L_{r 1}, L_{r 2}$ and $C_{r 2}$, and the resonant current $i_{L r 1}$ rises in a sine-wave curve. The current in magnetizing inductor $i_{L m}$ also increases but resonates considerably slower than $i_{L r l}$. Thus $L_{m}$ does not take part in the resonance phenomenon in this interval. On the secondary side, the rectified currents $i_{Q r 6}$ and $i_{Q r 7}$, which are carried by the anti-parallel diodes of $Q_{r 6}$ and $Q_{r 7}$, are proportional to the difference between the terms $i_{L r I}$ and $i_{L m}$.

Interval $2\left[t_{1}, t_{2}\right]$ : After attaining its peak value, $i_{L r l}$ begins to decline and at the instant $t_{l}$ becomes equal to the slowly rising magnetic current $i_{L m}$. The rectifier current on the secondary side decreases to zero, and the anti-parallel diodes of $Q_{r 6} \&$
$Q_{r 7}$ turn off under ZCS. The voltage on the resonant capacitor $C_{r 2}$ also resonates to its peak with the absolute value of $V_{C r 2}$. It will remain unchanged unless it excites again in the next resonance. The free resonance between $C_{r l}, L_{r l}$, and $L_{m}$ on the primary side is availed by the disconnection of $C_{r 2}$ and $L_{r 2}$.

Interval $3\left[t_{2}, t_{3}\right]$ : At time $t_{2}, Q_{i 1}$ and $Q_{i 2}$ turn off. $i_{L r l}$ begins to charge the parasitic capacitance of $Q_{i 1}$ and $Q_{i 2}$, and discharge that of $Q_{i 3}$ and $Q_{i 4}$ simultaneously. Since the value of the parasitic capacitance is small compared with that of the resonant capacitor $C_{r l}$, this time period is rather short with respect to the total switching period. Thus, the corresponding voltages on the aforementioned capacitance rise/decrease rapidly. This stage ends up with $v_{d Q i l, 2}$ reaching the input voltage and $v_{d Q i 3,4}$ decreasing to zero. At the end of this stage, the voltage applied on the resonant tank has changed polarity from positive $U_{\text {in }}$ to negative.

Interval $4\left[t_{3}, t_{4}\right]$ : When $Q_{i 3}$ and $Q_{i 4}$ are completely discharged, the resonant current $i_{L r l}$ immediately starts flowing through the anti-parallel body diodes of $Q_{i 3}$ and $Q_{i 4}$, and is fed back to the input source. When the voltage of the magnetic inductor $L_{m}$ resonates to reach the voltage of $V_{2}-V_{C r 2}$, the rectifier switches $Q_{r 5}$ and $Q_{r 8}$ conduct, and the resonant capacitor $C_{r 2}$ and $L_{r 2}$ participate the resonance with the primary side again. At time $t_{4}, Q_{i 3}$ and $Q_{i 4}$ turn on under ZVS conditions, the first-half switching period ends, and the converter enters the next (the second) half.

Interval 5 to 8: In the next half cycle, the operation of the converter is the same as in the first half cycle, except that the other pair of switches in both the inverting and rectifying stages are operating in the second half.

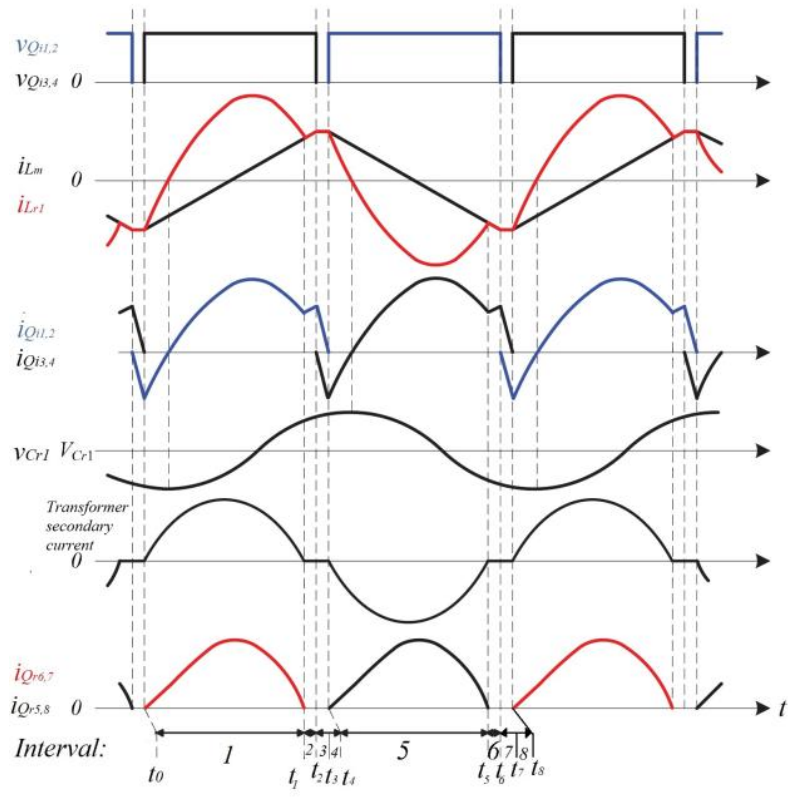

Fig. 3 Theoretical waveforms of the bidirectional CLL-LC converter 

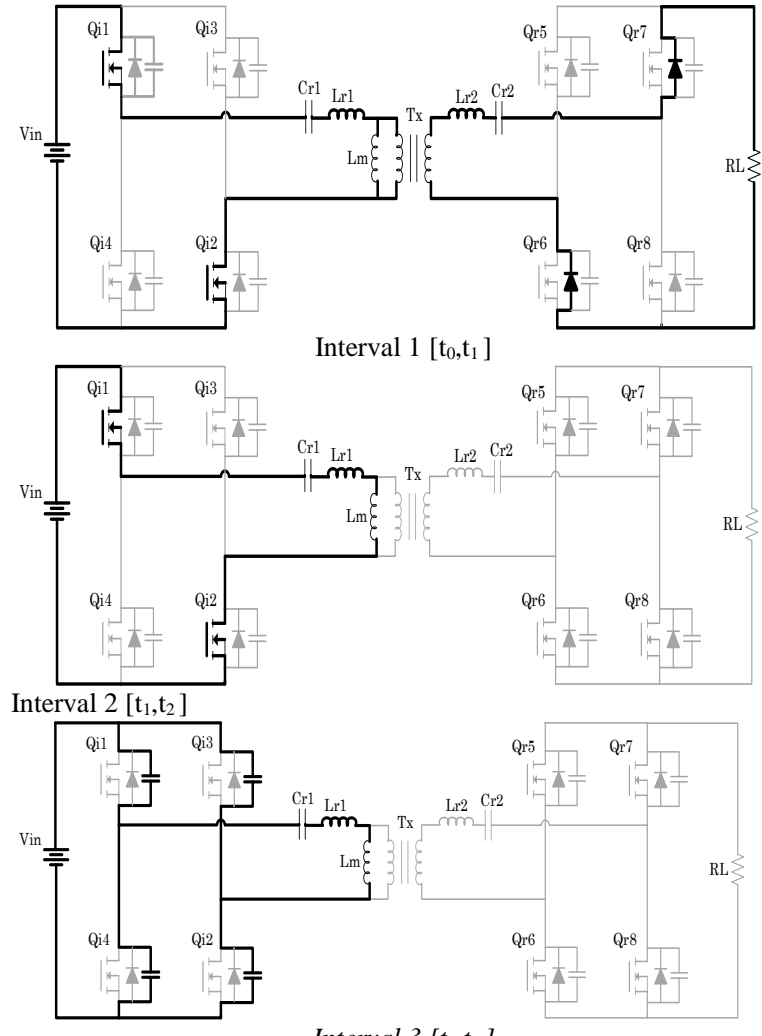

Interval $3\left[t_{2}, t_{3}\right]$

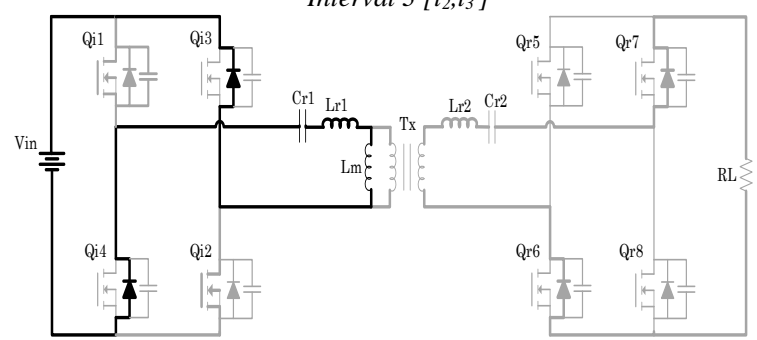

Interval $4\left[t_{3}, t_{4}\right]$

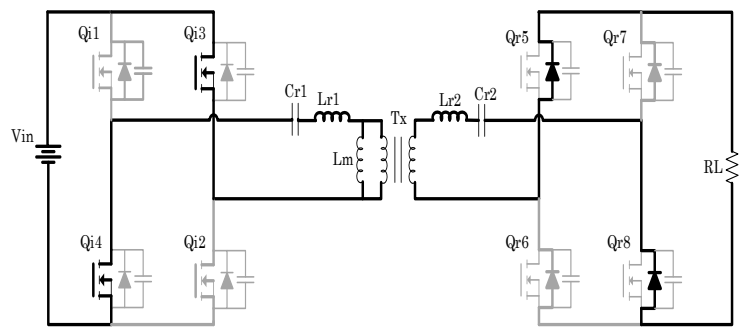

Interval $5\left[t_{4}, t_{5}\right]$

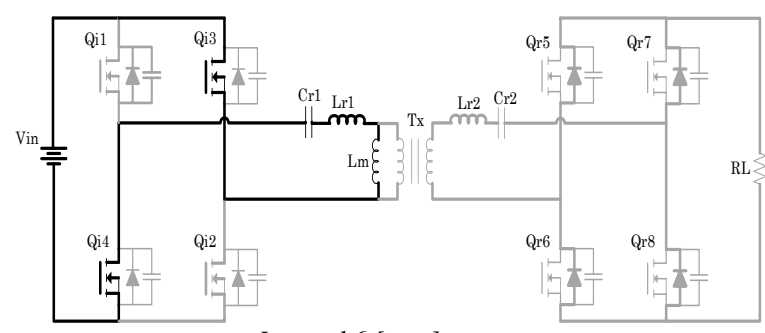

Interval $6\left[t_{5}, t_{6}\right]$

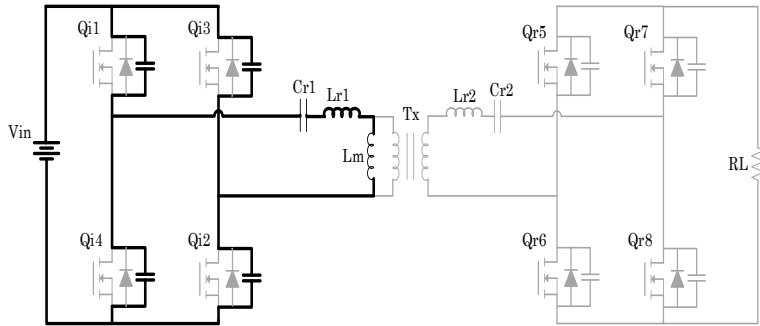

Interval $7\left[t_{6}, t_{7}\right]$

Fig. 4 Operation of the converter for different intervals

\section{SIMULATION RESULTS}

For the verification of theoretical analysis of CLLC resonant converter, simulation circuits for the forward and backward power transfer modes were built. The converter requirements are as given in the Table I.

Table I Converter Requirements

\begin{tabular}{|l|l|}
\hline \multicolumn{1}{|c|}{ Parameter } & Value \\
\hline Input voltage & $300-600 \mathrm{~V}$ \\
\hline Output voltage & $200-400 \mathrm{~V}$ \\
Nominal Vin & $450 \mathrm{~V}$ \\
Nominal Vout & $300 \mathrm{~V}$ \\
\hline Operation Frequency & $170 \mathrm{kHz}$ \\
\hline
\end{tabular}

The resonant network parameters used are as shown in Table II given below.

Table II Resonant Network Parameters

\begin{tabular}{|l|c|}
\hline \multicolumn{1}{|c|}{ Parameter } & Value \\
\hline $\mathrm{C}_{\mathrm{r} 1}$ & $51 \mathrm{nF}$ \\
\hline $\mathrm{L}_{\mathrm{r} 1}$ & $17.3 \mathrm{uH}$ \\
\hline $\mathrm{L}_{\mathrm{m}}$ & $69.2 \mathrm{uH}$ \\
\hline $\mathrm{C}_{\mathrm{r} 2}$ & $114 \mathrm{nF}$ \\
\hline $\mathrm{L}_{\mathrm{r} 2}$ & $7.7 \mathrm{uH}$ \\
\hline $\mathrm{n}$ & 1.5 \\
\hline & \\
\hline
\end{tabular}

The simulation results are given in Fig. 5 and Fig. 6. Fig. 5 shows the waveforms when output voltage is $300 \mathrm{~V}$ and an input voltage of $450 \mathrm{~V}$ with the operation frequency of 170 $\mathrm{kHz}$ in the forward operation mode. It can be seen that the primary MOSFETs are ZVS-ON and the rectifying anti-parallel diodes are ZCS-OFF. This leads to a reduction in switching losses. Also, it allows for use of high switching frequencies which leads to a reduction in the size of magnetic elements and filter capacitors thus reducing size, weight, volume and increasing power density.

As the structure of the converter is symmetrical, so the reverse mode operation exhibits the same features as the forward mode. Fig. 6 shows the reverse operation with an input of $300 \mathrm{~V}$ and output of 450 , as can be seen. It can be seen that $\mathrm{ZVS}-\mathrm{ON}$ is achieved for the inverting stage and ZCS-OFF is achieved for the rectifying stage switches. Thus the converter can operate in both directions with improved efficiency, diminished losses, and high frequency which leads to a reduction in the size, weight, and volume and an increase in the power density of the converter. 

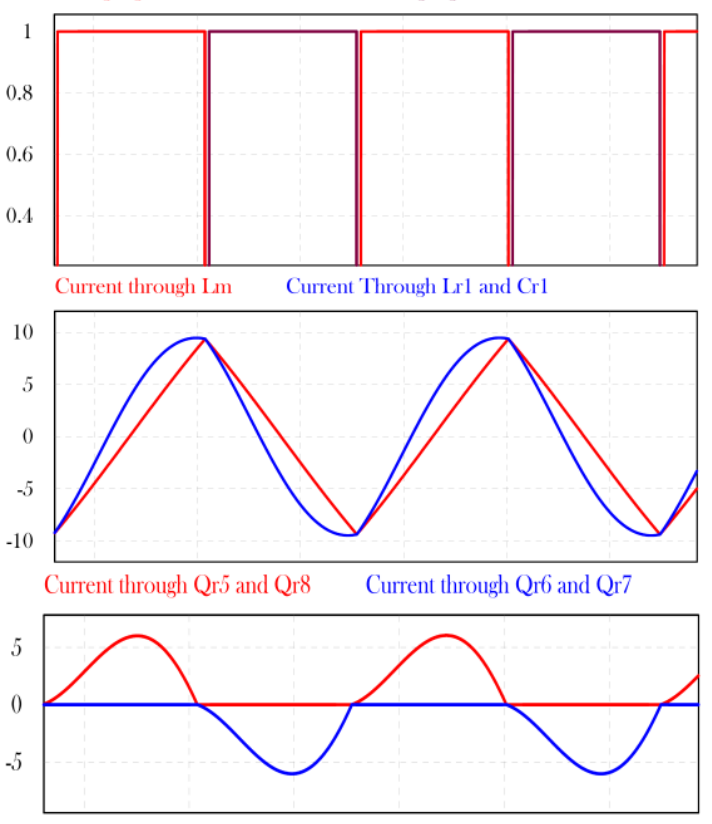

Output Voltage

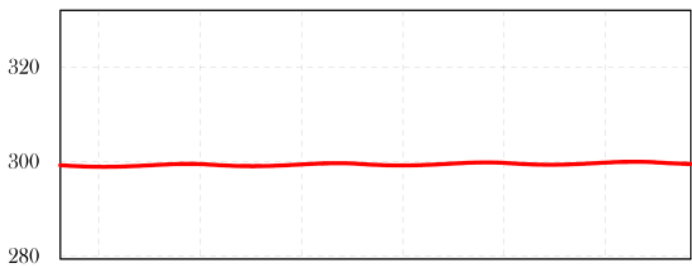

Fig. 5 Simulation Waveforms for input voltage of $450 \mathrm{~V}$ and output voltage of $300 \mathrm{~V}$ in forward mode
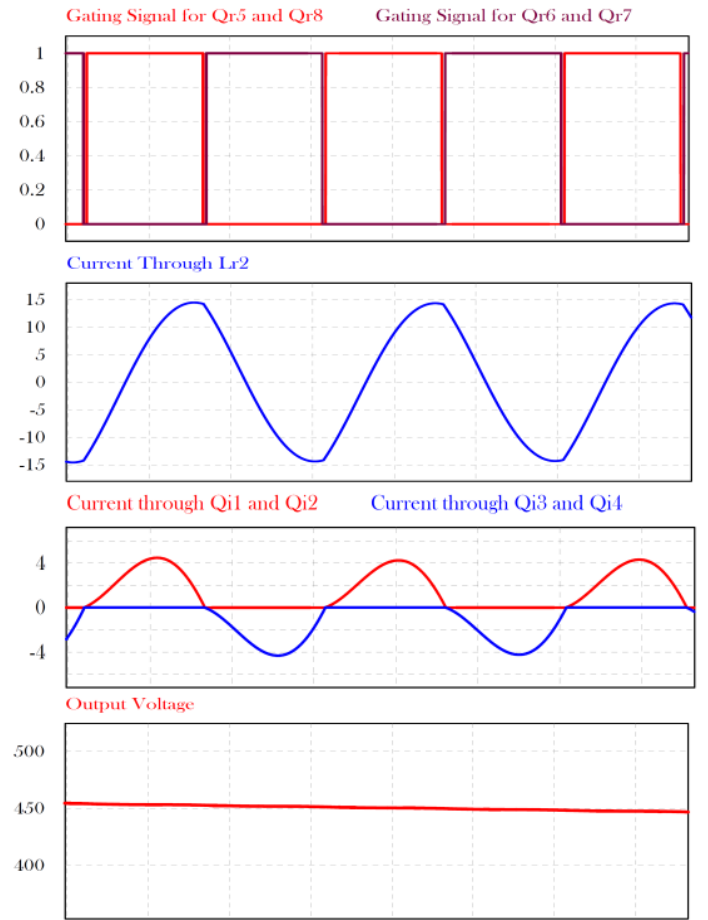

Fig. 6 Simulation Waveforms for input voltage of $300 \mathrm{~V}$ and output voltage of $450 \mathrm{~V}$ in reverse mode

\section{CONCLUSION}

The CLL-LC bidirectional DC-DC converter presented in this paper, which has a symmetric resonant tank, offers soft- switching as zero voltage switching for the inverting stage and zero current switching for the rectifier switches irrespective of the direction of flow of power. Thus, when MOSFETs are employed as the main switches, the converter has decreased switching losses and is totally snubberless offering reduced size, weight and volume. The operation principles and simulations of the proposed converter have been analyzed and depicted. It has been shown that the simulated converter exhibits ZVS for the inverting stage and ZCS for the rectifying stage. The simulation results validate the theoretical analysis and the merits of the converter. Keeping this in view, the converter offers itself as an alternative choice with wide input range, improved efficiency, and high power density particularly suited for on-board battery charging/discharging applications in electrical vehicles.

\section{REFERENCES}

[1] B. Zhao, Q. Song, W. Liu, and Y. Sun, "Overview of dual-active-bridge isolated bidirectional DC-DC converter for high-frequency-link power-conversion system,” IEEE Trans. Power Electron., vol. 29, no. 8, pp. 4091-4106, 2014.

[2] M. H. Kheraluwala and R. W. De Doncker, "Single phase unity power factor control for dual active bridgelnconverter," in Conf Rec. 28th IEEE Industry Applications Soc. (IAS) Annu. Meeting, 1993.

[3] M. N. Kheraluwala, R. W. Gascoigne, D. M. Divan, and E. D. Baumann, "Performance characterization of a high-power dual active bridge DC-to-DC converter," IEEE Trans. Ind. Appl., vol. 28, no. 6, pp. 1294-1301, 1992.

[4] W. L. X. He, "Operation, design and control of dual H-bridge-based isolated bidirectional DC-DC converter," IET Power Electron., vol. 2, no. July 2007, pp. 125-133, 2009.

[5] G. G. Oggier, R. Leidhold, G. O. García, A. R. Oliva, J. C. Balda, and F. Barlow, "Extending the ZVS operating range of dual active bridge high-power DC-DC converters," in PESC Record - IEEE Annual Power Electronics Specialists Conference, 2006.

[6] Hua Bai and C. Mi, "Eliminate Reactive Power and Inrreace Suctem Fffiriency of Isolated Bidirectional

IJCATM : www.ijcaonline.org -DC Converters Using Novel ," IEEE Trans. Power Electron., vol. 23, no. 6, pp. 2905-2914, Nov. 2008.

[7] G. G. Oggier, G. O. Garc??a, and A. R. Oliva, "Modulation strategy to operate the dual active bridge DCDC converter under soft switching in the whole operating range," IEEE Trans. Power Electron., vol. 26, no. 4 , pp. $1228-1236,2011$.

[8] J. Jung and J. Kwon, "Theoretical analysis and optimal design of LLC resonant converter," in 2007 European Conference on Power Electronics and Applications, 2007, pp. 1-10.

[9] J. H. Jung, "Bifilar winding of a center-tapped transformer including integrated resonant inductance for LLC resonant converters," IEEE Trans. Power Electron., vol. 28, no. 2, pp. 615-620, 2013.

[10] S. Y. Chen, Z. R. Li, and C. L. Chen, "Analysis and design of single-stage AC/DC LLC resonant converter," IEEE Trans. Ind. Electron., vol. 59, no. 3, pp. 1538-1544, 2012. 
[11] X. Fang, H. Hu, Z. J. Shen, and I. Batarseh, "Operation mode analysis and peak gain approximation of the LLC resonant converter," IEEE Trans. Power Electron., vol. 27, no. 4, pp. 1985-1995, 2012.

[12] J. Zhang, J. Liao, J. Wang, and Z. Qian, "A current-driving synchronous rectifier for an LLC resonant converter with voltage-doubler rectifier structure," IEEE Trans. Power Electron., vol. 27, no. 4, pp. 1894-1904, 2012.

[13] S. H. Cho, C. S. Kim, and S. K. Han, "High-efficiency and low-cost tightly regulated dual-output LLC resonant converter," IEEE Trans. Ind. Electron., vol. 59, no. 7, pp. 2982-2991, 2012.

[14] B. C. Hyeon and B. H. Cho, "Analysis and Design of the LmC Resonant Converter for Low Output Current
Ripple,” Ieee Trans. Ind. Electron., vol. 59, no. 7, pp. 2772-2780, 2012.

[15] J.-H. Jung, H.-S. Kim, M.-H. Ryu, and J.-W. Baek, "Design Methodology of Bidirectional CLLC Resonant Converter for High-Frequency Isolation of DC Distribution Systems," IEEE Trans. Power Electron., vol. 28, no. 4, pp. 1741-1755, Apr. 2013.

[16] W. Chen, P. Rong, and Z. Lu, "Snubberless bidirectional DC-DC converter with new CLLC resonant tank featuring minimized switching loss," IEEE Trans. Ind. Electron., vol. 57, no. 9, pp. 3075-3086, Sep. 2010.

[17] A. Hillers, D. Christen, and J. Biela, "Design of a Highly Efficient Bidirectional Isolated LLC Resonant Converter," 15th Int. Power Electron. Motion Control Conf., vol. 1, no. 3, p. DS2b.13-1-13-8, 2012. 